\title{
Precipitated calcium carbonate as carrier particles of 'dry liquids' for post-processing crosslinking reactions
}

\author{
Roland Vogel ${ }^{1^{*}}$, Marijan Vučak $^{2}$, Christoph Nover ${ }^{2}$, Lutz Peitzsch $^{1}$ \\ 1*Leibniz-Institut für Polymerforschung Dresden e. V., Hohe Straße 6, 01069 \\ Dresden, Germany, vogel@ipfdd.de \\ ${ }^{2}$ SCHAEFER KALK GmbH \& Co. KG, Louise-Seher-Straße 6, 65582 Diez, Germany
}

(Received: 07 March, 2011; published: 29 January, 2012)

\begin{abstract}
Precipitated calcium carbonates (PCC) of different particle morphologies were used as appropriate carrier particles for post-processing crosslinking reactions. Optimum particle morphology and size were estimated for preparation of dry liquids (DLs). The DLs were tested in three different typically crosslinking reactions of polymers.
\end{abstract}

\section{Introduction}

Dry Liquids (DLs) are mixtures with the appearance of a free flowing powder where the active ingredient, a liquid, is supported by a suitable carrier. In the polymer industry a wide range of liquids is used, such as crosslinking agents, accelerators, process oils, plasticisers, flame retardants and resins. Many of these liquids are difficult to handle and most are used on a regular rather than on a continuous basis. Low viscosity liquids are difficult to add to polymer melts in an extruder. High viscosity liquids, high tack liquids or low melting point solids are difficult to add accurately. By converting the physical form of these liquids to DLs the compounding step is made easier. Handling is easier, measurements are more accurate and there is less waste. In addition the DLs are often much faster to mix in, distribute more evenly and reduce cycle times. The most common carrier particles are silicas and silicates where the level of the active ingredient is typically $70-75 \mathrm{wt} .-\%$. Other carrier particles are possible but not so common.

Calcium carbonate in the form of chalk, whiting, marble, and limestone is perhaps the most widely available and utilized mineral additive in the world today. Calcium carbonates, especially, have long been recognized as useful additives for elastomers, thermoplastics and particularly in PVC for many applications. Ground calcium carbonate (GCC) is generally used as a filler with an interesting costperformance ratio. Precipitated calcium carbonate (PCC) is also a versatile additive for use in a wide range of plastic and elastomeric applications. Its regular particle morphology, size and particle size distribution, together with the possibility of hydrophobic surface modification, add up to benefit both polymer processing and subsequent physical properties. The specific structure and granulometry of precipitated calcium carbonates (PCCs) allows these materials to fulfil additional functions like aiding processing, improving strength properties and increasing 
weather stability. Recently new methods to obtain amorphous calcium carbonate (ACC) [1] and dried amorphous calcium carbonate (DACC) [2,3] have been reported. They can also be used as interesting additives in order to improve processing and polymer properties.

In this paper special attention is given to prevent the crosslinking reaction during melt processing. To do this, the crosslinker was trapped onto carrier particles of PCC. If the crosslinker is directly mixed with the functionalized polymer and the catalyst in the extruder, the uniform distribution of reactants leads to a crosslinked melt within a short time, depending only on the reaction rate between the crosslinker and the reactive functions grafted on the polymer backbone. When the crosslinker is first trapped on the carrier particles, it has to desorb from the particle surface and diffuse into the polymer matrix. Considering the short residence time in an extruder it is therefore expected that the crosslinker molecules will only react with the reactive groups of the polymer chains, which are close to the carrier particles. Consequently, after the melt processing step only small crosslinked domains should result around the carrier particles separated by unreacted matrix. In the last step of the process the shaped products are stored at a moderate temperature to allow further diffusion of the crosslinker from the carrier particles and therefore a chemical reaction throughout the whole volume, ending finally with a homogeneous crosslinking density.

This paper reports on an attempt to use precipitated calcium carbonates (PCCs) of different particle morphologies as appropriate carrier particles for three different postprocessing crosslinking reactions.

\section{Results and discussion}

\section{Preparation of DLs for evaluating PCCs as carrier particle}

Four different PCCs were selected in order to evaluate their use in preparing DLs in dependence on particle morphology (see Tab .1).

Tab. 1. Parameters of the used PCCs

\begin{tabular}{llcc}
\hline & crystal modification & $\begin{array}{c}\text { specific surface } \\
\mathrm{BET}\left[\mathrm{m}^{2} / \mathrm{g}\right]\end{array}$ & $\begin{array}{c}\text { particle size } \\
\mathrm{d}_{50 \%}[\mu \mathrm{m}]\end{array}$ \\
\hline PCC 1 & $\begin{array}{l}\text { calcite, } \\
\text { scalenohedral } \\
\text { calcite, }\end{array}$ & 8.7 & 1.0 \\
PCC 2 & $\begin{array}{l}\text { scalenohedral } \\
\text { calcite, } \\
\text { PCC 3 }\end{array}$ & 5.3 & 3.3 \\
PCC 4 4 & $\begin{array}{l}\text { calcite, } \\
\text { plate-like }\end{array}$ & 17.2 & 0.7 \\
& & & 1.0
\end{tabular}




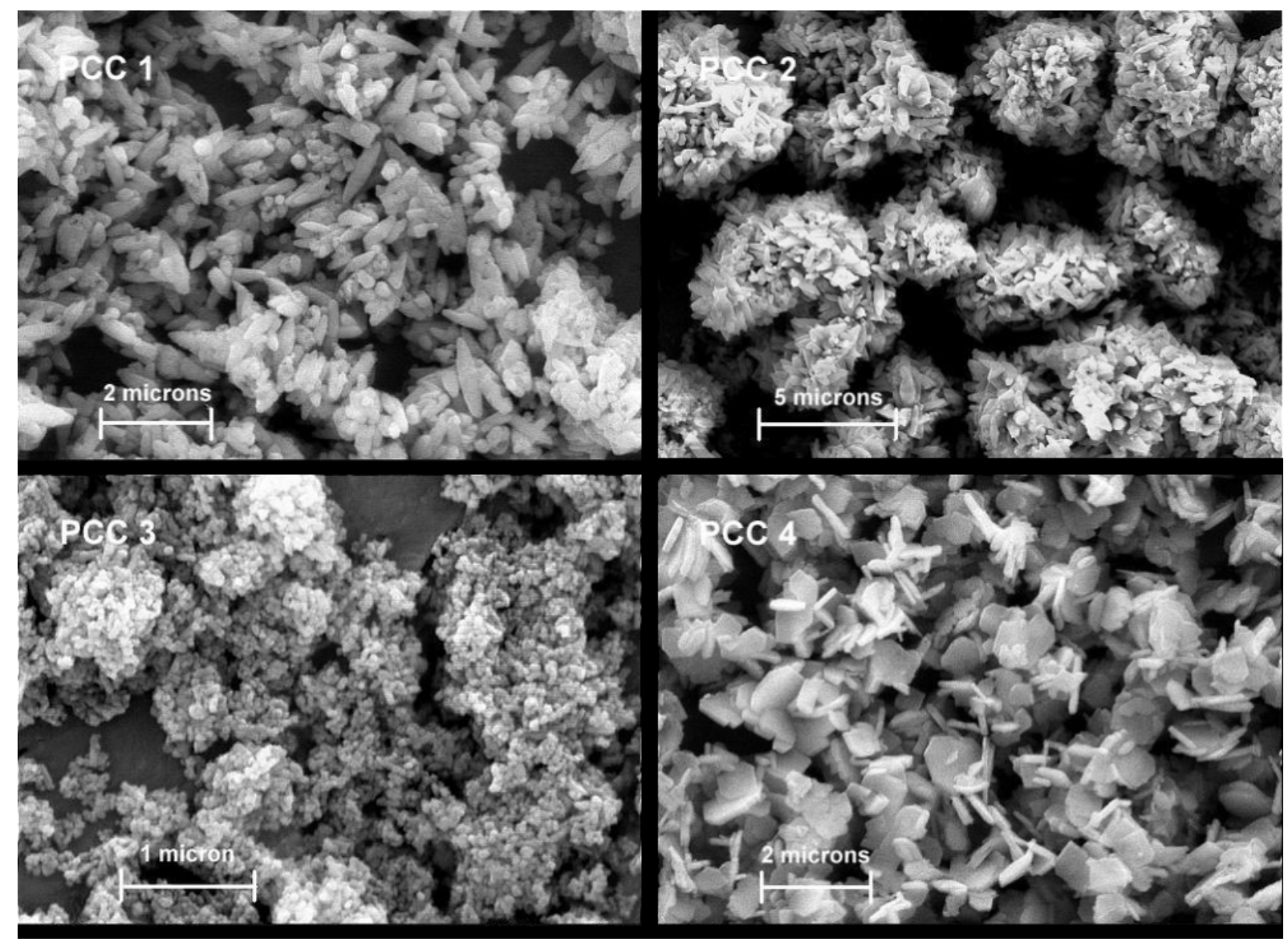

Fig. 2 SEM micrographs of the PCCs

Particle morphology of the used four PCCs can be seen in Fig. 1.

1,4-butanediol was selected as the active liquid ingredient. Then $1.2 \mathrm{~g}$ 1,4-butanediol was solubilised in $5 \mathrm{~mL}$ of tetrahydrofuran to decrease its viscosity. In each case 1.2 $\mathrm{g}$ of the PCC was then easily dispersed in this solution. After $24 \mathrm{~h}$ at room temperature the solvent had evaporated and dry powders were obtained. To eliminate all remaining solvent the powder was maintained at $120{ }^{\circ} \mathrm{C}$ during $20 \mathrm{~min}$. Then it was checked that the final weight corresponded to the sum of that of the particles and that of the diol. It was found that all the diol was trapped on the carrier particles. DLs prepared using PCC 1, PCC 2 and PCC 3 resulted in sticky, poorly flowing powders. Only the DL with PCC 4 yielded a suitable free-flowing powder with the highest bulk density. Because of this all further studies were carried out using PCC 4 as carrier particles.

Post-processing crosslinking of an ethylene/butylacrylate copolymer grafted with maleic anhydride

Abbas et al. [4] reported a new way to process functionalized polymer materials that are able to crosslink. The crosslinking reaction occurs after the melt processing step and without the addition of external reagents. The chemical reaction involved in the crosslinking process is the reaction between a succinic anhydride and a hydroxyl function. This reaction has been extensively described [4-6]. The processing temperatures used by the authors [4] were below $150{ }^{\circ} \mathrm{C}$, so that they considered that only one acid function per succinic anhydride group could react with the hydroxyl 
function. Maleic anhydride-ethylene/butylacrylate copolymer was processed with 1,4butanediol in the presence of para-toluene sulfonic acid as catalyst. Abbas et al. [4] used microporous spherical polyamide 12 particles with a diameter equal to $5 \pm 1 \mu \mathrm{m}$ as carrier particles. In our paper PCC 4 was used as carrier particles. $2 \mathrm{~g}$ 1,4butanediol was solubilised in $5 \mathrm{ml}$ of tetrahydrofuran. Then $2 \mathrm{~g}$ of PPC 4 were dispersed in this solution. After drying the DL could be used for the processing step. $4 \mathrm{~g}$ of the polymer matrix, $0.12 \mathrm{~g}$ of the $\mathrm{DL}$ and $0.008 \mathrm{~g}$ of the catalyst were mixed in a micro compounder at a processing temperature of $110{ }^{\circ} \mathrm{C}$. The mixing time was 4 minutes and the mixing speed was set at $50 \mathrm{rpm}$.

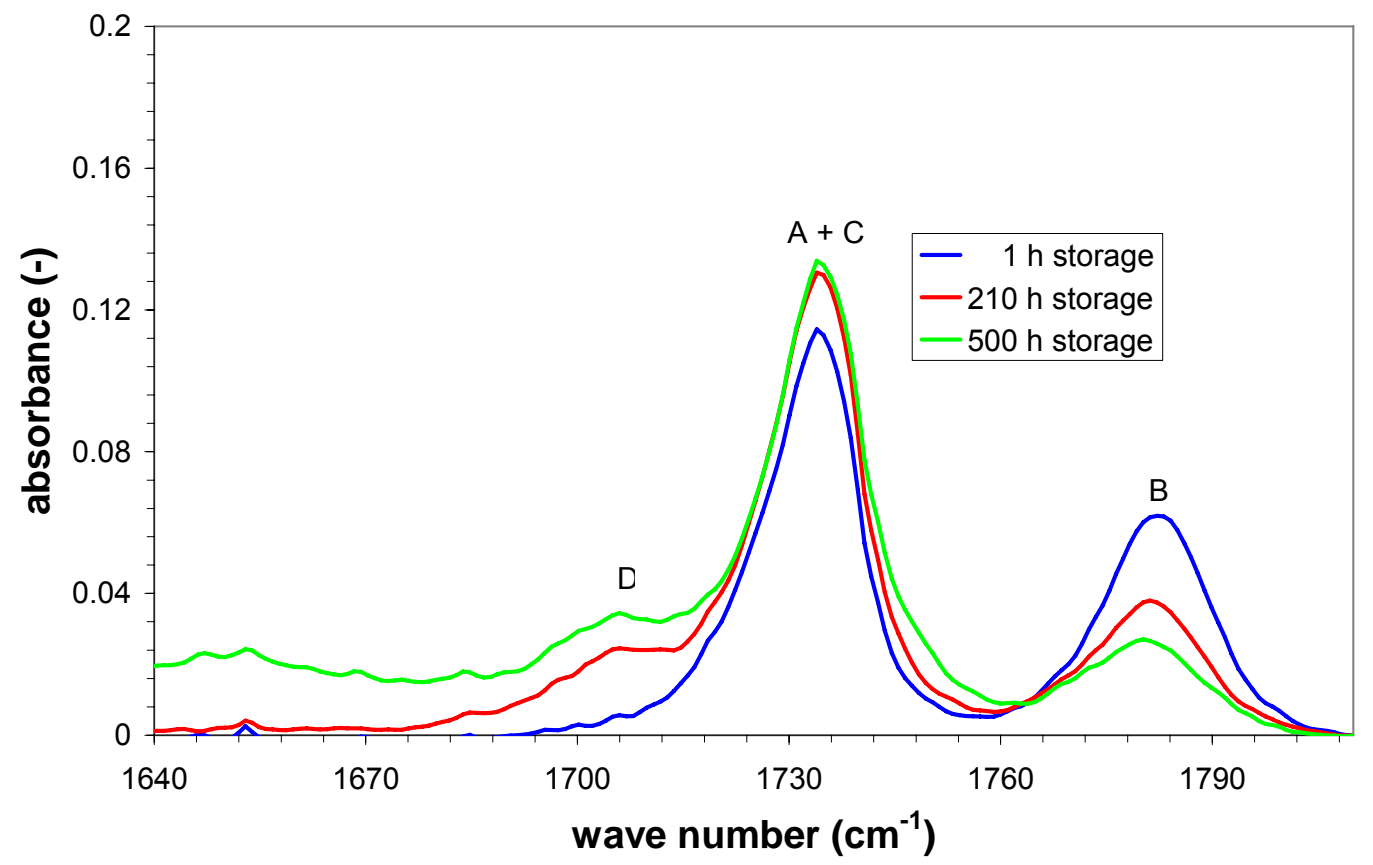

Fig. 2 Normalized ATR-FTIR spectra of the crosslinked products after 1, 210 and $500 \mathrm{~h}$ storage

Fig. 2 shows ATR-FTIR spectra for different times of storage of the mixed samples, for a wave number range from 1660 to $1820 \mathrm{~cm}^{-1}$. The peak at $1780 \mathrm{~cm}^{-1}$ (B) is associated with the asymmetric ring vibration of the succinic anhydride. The peak at $1740 \mathrm{~cm}^{-1}$ can be described as the combination of the carbonyl stretch band of the ester function (D) and of butyl acrylate (A). The shoulder at $1695 \mathrm{~cm}^{-1}$ is related to the carbonyl stretch band of the acid functional group (C). The intensity of the $B$ and $C$ peaks, respectively, decreased and increased with the time of storage inferring that the chemical reaction occurred through succinic anhydride ring-opening as described in [4], that for each succinic anhydride opened, a carboxylic acid is formed. A comparison of the spectra in Fig. 1 with the results reported by Abbas et al. [4] leads to the conclusion that the same crosslinking reaction has occurred. The gel fraction of the crosslinked copolymer was determined after extraction during $16 \mathrm{~h}$ in a Soxhlet device using toluene as solvent of the soluble fraction. The initial mass of the samples was close to $0.2 \mathrm{~g}$. A gel content of $48 \mathrm{wt} .-\%$ was found after $500 \mathrm{~h}$ storage of the sample. 


\section{Photo-crosslinking of metallocene polyethylene}

The photo-crosslinking of polyethylene is well described in technical literature [7-9]. A typical photoreaction was selected for the postprocessing crosslinking of a metallocene polyethylene [7]. Triallylisocyanurate (TAC) and dimethylolpropane tetraacrylate (DTMPTA) were selected as crosslinker. 4-chlorbenzophenone (CP) was used as an effective photoinitiator [7]. PCC 4 again served as carrier particles. In each case $0.5 \mathrm{~g}$ of the crosslinkers and $0.5 \mathrm{~g}$ of the CP were solubilised in $10 \mathrm{ml}$ of ethanol for preparation of the DLs. Then $2 \mathrm{~g}$ of PCC 4 were dispersed in these solutions. After this the DLs were dried for $24 \mathrm{~h}$ at room temperature. The compositions described in Tab. 2 were mixed in a micro compounder at a processing temperature of $130{ }^{\circ} \mathrm{C}$ and a mixing time of 5 min. The mixing speed was set at 80 rpm.

Tab. 2. Compositions for the photo-crosslinking of $\mathrm{mPE}$

\begin{tabular}{lc}
\hline sample & composition \\
\hline mPE A & $3.5 \mathrm{~g} \mathrm{mPE}$ \\
$\mathrm{mPE} \mathrm{B}$ & $3.5 \mathrm{~g} \mathrm{mPE}+0,07 \mathrm{~g} \mathrm{TAC}+0.07 \mathrm{~g} \mathrm{CP}$ \\
$\mathrm{mPE} \mathrm{C}$ & $3.5 \mathrm{~g} \mathrm{mPE}+0.07 \mathrm{~g}$ DTMPTA $+0.07 \mathrm{~g} \mathrm{CP}$ \\
$\mathrm{mPE} \mathrm{D}$ & $0.42 \mathrm{~g} \mathrm{DL}$ containing TAC \\
$\mathrm{mPE}$ E & $0.42 \mathrm{~g} \mathrm{DL}$ containing DTMPTA
\end{tabular}

Samples MPE B and MPE C were directly mixed without using DLs for comparison of the different crosslinking processes. After mixing, the samples were heat pressed to films with a thickness $0.5 \mathrm{~mm}$ at $130{ }^{\circ} \mathrm{C}$ using a hot press. Then the samples were irradiated at room temperature under ambient atmosphere in a UV-cure device constructed in our laboratory. The UV lamp used was a high-pressure mercury lamp, operated at $1 \mathrm{~kW}$, at a distance of $5 \mathrm{~cm}$ from the sample surface.

Oscillatory rheological measurements were done with the pristine sample and the irradiated sheets at $120^{\circ} \mathrm{C}$. Fig. 3 shows the storage modulus G' of the samples. It can be seen that all four samples containing crosslinker and photoinitiator demonstrate a distinctly higher modulus in lower frequency ranges. This effect is a clear-cut indication that the samples are crosslinked. 




Fig. 3 Storage modulus of the pristine MPE and the crosslinked samples

The gel fraction of the crosslinked mPE was determined after extraction during $18 \mathrm{~h}$ in a Soxhlet device using xylene as solvent of the soluble fraction. The initial mass of the samples was close to $0.2 \mathrm{~g}$. The results are compiled in Tab. 3 .

Tab. 3. Gel content of the mPE samples

\begin{tabular}{cc}
\hline sample & $\begin{array}{c}\text { gel content } \\
\text { wt.-\% }\end{array}$ \\
\hline mPE A & 0 \\
mPE B & 66 \\
mPE C & 63 \\
mPE D & 65 \\
mPE E & 67
\end{tabular}

The rheological properties and the gel content of the crosslinked samples show almost the same values. There is no obvious difference between the directly mixed samples and the samples mixed using DLs. But the processing of the samples with DLs is advantageous because of the easier handling and more accurate measurement.

\section{Silan-grafting and post-processing crosslinking of isotactic polypropylene}

In the silane crosslinking technique, unsaturated hydrolyzable alkoxysilanes are first grafted onto polyolefins; grafted products are then processed and shaped using conventional thermoplastic equipment, followed by catalyzed crosslinking of the products in the presence of trace amounts of water. The crosslinking of isotactic polypropylene (iPP) using this method is reported in $[10,11]$. 3- 
methacryloxypropyltrimethoxysilane (VMMS) was selected as crosslinker for our experiments. The solid benzoyl peroxide (BPO) was used as radical initiator for the grafting of VMMS on the iPP. Phenylethylene (styrene) was added to improve the grafting reaction. PCC 4 was selected as carrier particles. For preparation of the DL $0.36 \mathrm{~g}$ BPO, $1 \mathrm{~g}$ VMMS and $0.12 \mathrm{~g}$ styrene were solubilised in $7 \mathrm{ml}$ acetone. Then $1.5 \mathrm{~g}$ of the PCC was dispersed in the solution. The solvent was vaporized after $24 \mathrm{~h}$ storage at room temperature, followed by drying for $15 \mathrm{~min}$ at $130{ }^{\circ} \mathrm{C}$. A combination of $4 \mathrm{~g}$ iPP and of $0.0592 \mathrm{~g} \mathrm{DL}$ was mixed in a micro compounder at a processing temperature of $215^{\circ} \mathrm{C}$. The mixing time was 4 min and the mixing speed was set at $75 \mathrm{rpm}$. Then the product was stored in a water bath for 3 days at $55^{\circ} \mathrm{C}$. The water bath contained the required catalyst dibutyltin dilaurate (DBTL) with a concentration of 0.02 wt.-\%.

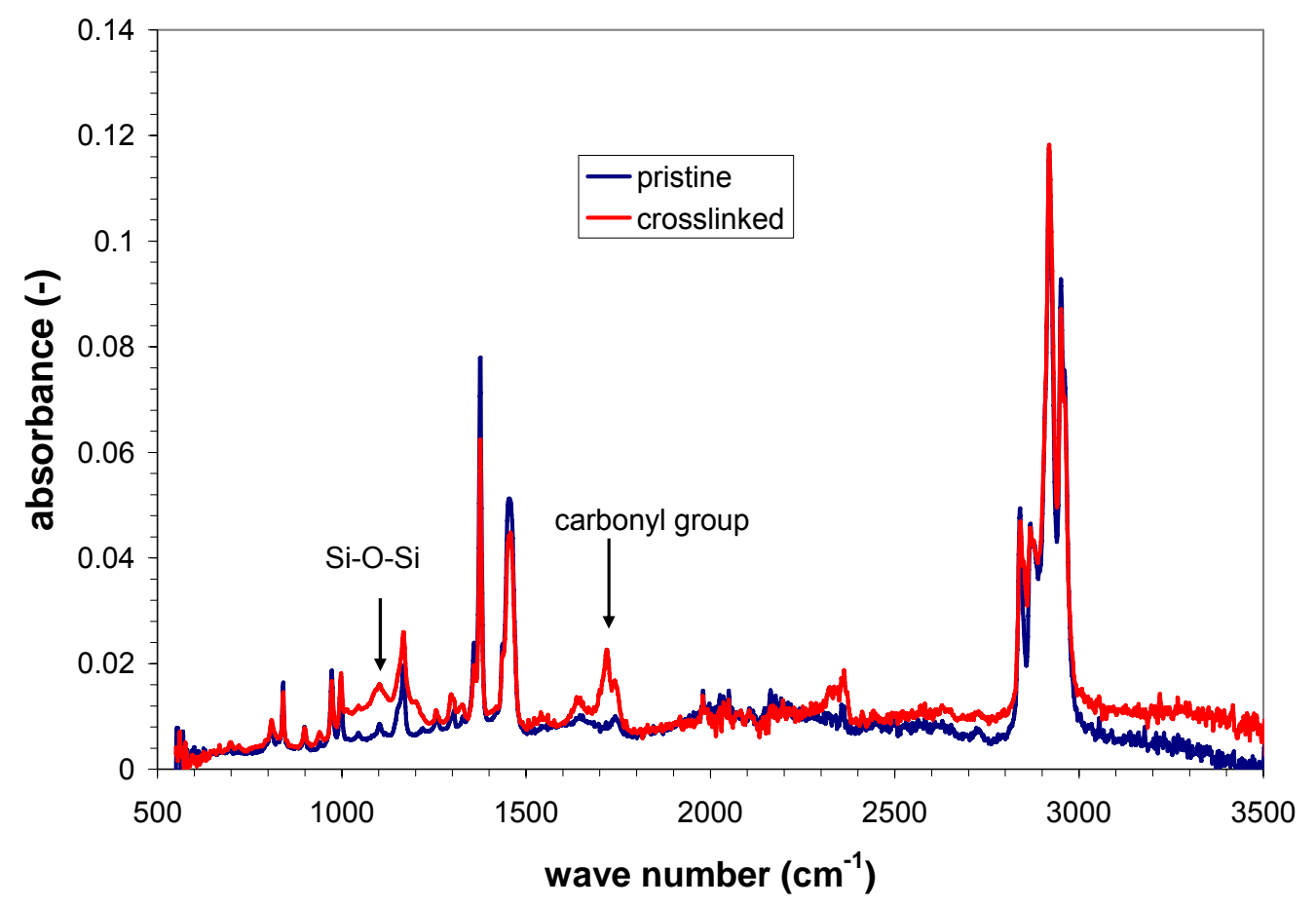

Fig. 4 ATR-FTIR spectra of the iPP matrix and the crosslinked product

Fig. 5 shows the ATR-FTIR spectra of the pristine iPP matrix and the crosslinked product. The spectrum of the crosslinked product clearly shows two new absorbance bands at 1741 and $1100 \mathrm{~cm}^{-1}$, which are characteristic bands of carbonyl group $\left(1741 \mathrm{~cm}^{-1}\right)$ and $\mathrm{Si}-\mathrm{O}$ Si bond $\left(1100 \mathrm{~cm}^{-1}\right)$. There is a carbonyl group in the structure of the VMMS, and the silane grafting and crosslinking produces $\mathrm{Si}-\mathrm{O}-\mathrm{Si}$ groups [11]. The gel fraction of the crosslinked iPP was determined after extraction during $12 \mathrm{~h}$ in a Soxhlet device using xylene as solvent. A gel content of $57 \mathrm{wt} . \mathrm{\%}$ was measured. By combining the results from the FTIR with the high gel content of the crosslinked iPP, it can be confirmed that silane crosslinking has occurred.

\section{Conclusions}

PCC as new carrier particles for post-processing crosslinking of polymers was tested. The discussed crosslinking method is based on the temporary trapping of one or all of the reactants through their adsorption on suitable carrier particles. It was shown that the process lead to a limited crosslinking extent at the end of the melt processing 
step as well as to highly and homogeneously crosslinked products after suitable storage or UV irradiation.

Different PCCs have been tested for preparation of DLs. The best results, corresponding to the best flow properties of the powders, were obtained with the plate-like particle morphology.

Using PCC as carrier particles for DLs presents several' advantages:

1. The PCC can be mixed with the active ingredient up to a weight ratio of $1: 1$.

2. The dispersed particles in the polymer show a very small particle/particle distance because of the small particle size of the PCC in comparison with other carrier particles. This effect results in short diffusion distances for the active ingredients of the DLs. Therefore the storage time for the diffusion of the active ingredients into the polymer matrix after the processing step can be shortened.

3. PCCs are often used as suitable polymer filler materials. PCC as filler can be combined with the DL made with PCC as a functionalised additive. The goals of filling and functionalising of the polymer matrix can thereby be attained in one step.

\section{Experimental part}

\section{Precitipated calcium carbonate}

The used PCCs were provided by the SCHAEFER KALK GmbH \& Co. KG, Diez, Germany.

\section{Chemicals}

The DTMPTA Ebecryl ${ }^{\mathrm{TM}} 140$ was obtained from Cytec and the TAC was purchased from Cytec Surface Specialties, The Netherlands. The chemicals para-toluene sulfonic acid, 1,4-butanediol, 4-chlorbenzophenone, 3-methacryloxypropyltrimethoxysilane, benzoyl peroxide, phenylethylene, and dibutyltin dilaurate were purchased from Sigma-Aldrich.

All the above commercial chemicals were used as received without further purification.

\section{Polymers}

The maleic anhydride-ethylene/butylacrylate copolymer LOTADER $囚$ (MAH) E-EAMAH 8200 (containing $6.5 \%$ ester and $2.8 \%$ maleic anhydride) was purchased from Arkema.

The mPE ENGAGE $®$ EG 8200, purchased from DuPont Dow Elastomers, was used as the basic material for the photo-crosslinking. It is a saturated ethylene-octene copolymer containing 12.5 mol-\% octene-comonomers.

The iPP HG455FB for silane crosslinking was purchased from BOREALIS. It is a polypropylene homopolymer intended for fiber applications. 


\section{Methods}

The micro compounder used for the melt processing step was a micro-scale twin screw extruder Micro 5, DSM Research, The Netherlands.

The basic rheological measurements in the melt state were carried out by means of an ARES rotational rheometer, Rheometric Scientific, Inc., USA, using small amplitude oscillatory frequency sweeps. The selected geometry for frequency sweeps and heating/cooling sweeps in the molten state was the parallel plate geometry (gap of about $2 \mathrm{~mm}$ and diameter of $25 \mathrm{~mm}$ ).

ATR-FTIR spectroscopy was conducted with a Bruker Tensor 27 FT-IR spectrometer (Bruker Optics Inc.) with a Golden Gate MKII ATR accessory (Specac). Each spectrum comprises 16 scans measured at a spectral resolution of $4 \mathrm{~cm}^{-1}$. Absorbance spectra were acquired with OPUS MIR Tensor 27 software version 4.0 (Bruker Optics Inc.).

The SEM micrographs were taken with Carl Zeiss DSM 962 (10 kV).

\section{References}

[1] Faatz, M.; Gröhn, F.; Wegner, G. Adv. Mat. 2004, 16, 996.

[2] Gorna, K.; Hund, M.; Vučak, M.; Gröhn, F.; Wegner, G. Mat. Sci. Eng. A 2008, 477, 217.

[3] Gorna, K.; Vučak, M.; Hund, M.; Stöver, H.-D.; Wegner, G. Kunststoffe 2007, 100.

[4] Abbas, L.; Bouquey, M.; Flat, J. J.; Muller, R. Eur. Polym. J. 2008, 44, 1238.

[5] Siegel, E. F.; Moran, M. K. J. Am. Chem. Soc. 1947, 69, 1457.

[6] Triverdi, B. C.; Culbertson, B. M. Maleic anhydride (New York: Plenum Press; 1982).

[7] Chen, Y. L.; Rånby, B. J. Polym. Sci.: Part A: Polym. Chem. 1989, 27, 4051.

[8] Wu, Q.; Qu, B. Polym. Eng. Sci. 2001, 41, 1220.

[9] Wilski, H. Angewandte Chemie 1959, 71, 612.

[10] Huang, H.; Lu, H. H.; Liu, N. C. J. Appl. Polym. Sci. 2000, 78, 1233.

[11] Yang, S.; Song, G.; Zhao, Y.; Yang, Ch.; She, X. Polym. Eng. Sci. 2007, 47, 1004. 